\title{
Associations between apolipoprotein E phenotype, glucose metabolism and cognitive function in men. An explorative study in a population sample
}

\author{
E-L. Helkala*, T. Lakka†‡, M. Vanhanen§, T-P. Tuomainen‡, C. Ehnholm**, G.A. Kaplan†† \\ and J.T. Salonenł
}

* Department of Public Health and General Practice of University of Kuopio, Kuopio, Finland, tResearch Institute of Public Health, University of Kuopio and $\neq$ Research Institute of Exercise Medicine, Kuopio, § Department of Neurology, University Hospital and University of Kuopio, Kuopio, Finland, **National Public Health Institute, Helsinki, Finland, †+Department of Epidemiology, University of Michigan, School of Public Health, Ann Arbor, Michigan, USA

Accepted 10 May 2001

\begin{abstract}
Aims To investigate the associations of the apolipoprotein E phenotype (apoE) and disturbed glucose metabolism with cognitive function in a random population sample.
\end{abstract}

Methods A cross-sectional study was conducted, in which 528 men aged 54 or 60 years were recruited randomly from a larger population-based sample of 1516 men. A subject was defined as having abnormal glucose tolerance (AGT), if he had a clinical diagnosis of diabetes, with either dietary or oral antidiabetic treatment or showed impaired glucose tolerance in an oral glucose tolerance test. The subjects were divided into three groups according to apolipoprotein E phenotypes: (a) E2/4, E3/4 or E4/4 (apoE E4); (b) E 3/3 (apoE E3); and (c) E2/2 or E2/3 (apoE E2). Memory function was examined using a word-list learning with Buschke's selective reminding method and test. Executive functions were assessed with the Trail Making Test A and B.

Results Those subjects with apoE E2 and abnormal glucose metabolism demonstrated the worst cognitive executive control compared to other groups. Simple cognitive speed did not differ between the groups.

Conclusions The exploratory analyses revealed that subjects with apoE E2 allele and AGT had worse glycaemic control and cognitive executive control compared to other groups. Different apolipoprotein phenotypes together with impaired glucose tolerance may have different cumulative adverse effects on age-related cognitive performance. Some subgroups of subjects may be especially vulnerable to cognitive impairment.

Diabet. Med. 18, 991-997 (2001)

Keywords cognitive functions, glucose metabolism, apolipoprotein E phenotype

\begin{abstract}
Abbreviations AGT, abnormal glucose tolerance; NGT, normal glucose tolerance; apoE, apolipoprotein E phenotype; OGTT, $2 \mathrm{~h}$ oral glucose tolerance test; IDDM, insulin-dependent diabetes mellitus; NIDDM, noninsulin-dependent diabetes mellitus; IGT, impaired glucose tolerance; TMT A, Trail Making Test A; TMT B, Trail Making Test B; KIHD, Kuopio Ischemic Heart Disease Risk Factor Study
\end{abstract}

Correspondence to: Eeva-Liisa Helkala, PhD., Department of Public Health and General Practice, University of Kuopio, P.O.Box 1627, SF-70211 Kuopio, Finland. E-mail: Eeva-Liisa.Helkala@uku.fi

\section{Introduction}

The apolipoprotein E (apoE) E4 allele is an important risk factor for Alzheimer's disease [1,2]. The apoE E4 allele has 
also been associated with decreased cognitive function in discordant twin pairs [3]. In that study, the authors suggest that E4 may represent a potential marker for accelerated cognitive ageing. Episodic memory decline [4] or cognitive decline [5] has been shown in older adults carrying the apoE E4 allele. The apoE E2 allele may play a protective role in normal ageing [6]. A cross-sectional study showed that the $\mathrm{E} 2$ allele is associated with better learning ability in nondemented elderly subjects [7]. A longitudinal population-based study showed that subjects with the apoE phenotypes $\mathrm{E} 2 / 2$ or $2 / 3$ were able to maintain their verbal learning performance, while the learning ability of subjects with other apoE phenotypes deteriorated [8].

Patients with noninsulin-dependent diabetes mellitus (NIDDM) often show mild cognitive impairment $[9,11,12]$. It has been suggested that the presence of apoE phenotypes containing the $\mathrm{E} 4$ allele and cerebrovascular disease may have a synergistic effect on cognitive decline $[13,14]$. We investigated whether different apoE phenotypes and diabetes or impaired glucose tolerance had a cumulative adverse effect on cognitive performance in a population-based sample of middle-aged men in eastern Finland. In addition, we assessed the role of possible mediators of this relationship, such as control of glucose and lipid metabolism and cardiovascular diseases.

\section{Subjects and methods}

\section{Subjects}

The subjects were participants in the Kuopio Ischemic Heart Disease Risk Factor Study (KIHD). The recruitment of the subjects has been explained in detail previously [15]. The KIHD study was approved by the Research Ethics Committee of the University of Kuopio, Kuopio, Finland and all subjects gave written informed consent. The second cohort of the study population of the KIHD consisted of 1516 men aged 42, 48, 54 and 60 years $(82.6 \%$ of those eligible) at the time of examination. A total of 1229 men underwent ultrasound examination of the right and left carotid arteries. The group was invited to participate in a follow-up study four years later. Cognitive examination was performed in the two oldest age groups of 555 men. Nine men did not participate in the cognitive examination. Due to missing data on glucose metabolism, 528 men were included in the final analyses. Of these men, none were receiving insulin treatment, 43 had NIDDM and 105 had IGT, according to the WHO criteria [16].

\section{Methods}

\section{Measurement of glucose tolerance}

A $2 \mathrm{~h}$ oral glucose tolerance test (OGTT) was performed with a $75 \mathrm{~g}$ glucose load after at least $12 \mathrm{~h}$ of overnight fasting. Blood glucose was measured from fresh whole blood prior to, and two hours after, the glucose load using the glucose dehyrogenase method, after precipitation of proteins with tricloracetic acid.

\section{Definition of NIDDM and IGT}

A subject was considered to have noninsulin-diabetes (NIDDM) if he had a clinical diagnosis of diabetes and was undergoing either dietary or oral antidiabetic treatment or had a fasting venous blood glucose $\geqslant 6.7 \mathrm{mmol} / \mathrm{L}$ or $2 \mathrm{~h}$ venous blood glucose $\geqslant 10.0 \mathrm{mmol} / \mathrm{L}$. IGT was defined as a fasting venous blood glucose $<6.7 \mathrm{mmol} / \mathrm{L}$ and $2 \mathrm{~h}$ venous blood glucose 6.7 $10.0 \mathrm{mmol} / \mathrm{L}$. A subject was defined as having an abnormal glucose tolerance (AGT) if he had either NIDDM or IGT.

\section{Measurement of serum insulin}

Fasting and $2 \mathrm{~h}$ serum insulin in OGTT was determined from frozen serum samples with radioimmunological methods (Pharmacia, Uppsala, Sweden). Serum glycated proteins were measured with an autoanalyser (Kone Specific, Espoo, Finland).

\section{Resting blood pressure}

This was measured between 8:00 and 9:00 a.m. using a randomzero mercury sphygmomanometer (Hawsley, United Kindom). After a supine rest of five minutes, three measurements were taken in the supine, one in the standing and two in the sitting position at five minutes intervals. The mean of these six measurements was used.

\section{Waist-to-hip ratio}

The waist-to-hip ratio was computed as the ratio of the circumference of the waist to the circumference of the hip.

\section{Body mass index}

This was calculated as weight divided by height squared $\left(\mathrm{kg} / \mathrm{m}^{2}\right)$.

\section{Medical history}

This was recorded with a self-administered questionnaire, checked by a physician.

\section{The apolipoprotein E phenotype}

This was determined from plasma with isoelectric focusing and immunoblotting techniques [17]. The subjects were divided into three groups according to apolipoprotein E phenotypes. Subjects having one or two apolipoprotein $\varepsilon 4$ alleles were included in the apoE E4 group. Subjects with the most common apolipoprotein E phenotype, E3/3, formed the apoE E3 group and subjects with apolipoprotein E2/2 or E2/3 made up the apoE E2 group.

\section{Cognitive measurements}

Memory function was examined using a word-list learning test using Buschke's selective reminding method (BSRT) [18]. The subjects were read 10 unrelated words and were asked for immediate recall of the entire list. On the second trial, the subjects were read only those words that they failed to recall on the first trial and were again asked to recall the entire list. The score was the sum of words recalled on six trials. Executive functions were examined by the Trail Making Test A (TMTA) and B (TMTB) [19]. In Trail Making Test B, the letters were replaced with the names of the months using the first three letters of each month. The time in seconds to complete each trial was recorded. A maximum time of $150 \mathrm{~s}$ for Trail Making Test A, 
and $300 \mathrm{~s}$ for Trail Making Test B were allowed. If the test was not completed in the time allowed, the missing letters or numbers were scored as errors. The difference between times to complete the $\mathrm{A}$ and $\mathrm{B}$ parts was used as an indication of cognitive difficulty in changing between targets.

\section{Statistical analysis}

Statistical analyses were conducted with the SPSS for Windows Release 9.0. The differences between the groups were assessed uisng analysis of variance. The $\chi^{2}$-test was used for dichotomous variables.

The association of apoE phenotype and AGT on cognitive impairment was analysed with analysis of variance adjusted for age group and education. We also adjusted the results for possible confounders: serum HDL cholesterol, BMI, cardiovascular diseases and medication. We furthermore adjusted the results for serum glycated proteins, fasting serum blood glucose, $2 \mathrm{~h}$ blood glucose, fasting serum insulin, or $2 \mathrm{~h}$ serum insulin.

\section{Results}

\section{Characteristics of ApoE and AGT groups}

Percentages of subjects in the two age groups were similar in the different apoE groups. Education did not differ between the different apoE groups. The subjects with apoE E2 had higher fasting blood glucose, 2 h glucose, fasting insulin, and serum triglycerides than subjects with other phenotypes (Table 1). Education or age group distribution did not differ between the NGT and AGT groups (data not shown). AGT was related to higher BMI, waist-to-hip ratio, serum glycated proteins, fasting and $2 \mathrm{~h}$ blood glucose, fasting and $2 \mathrm{~h}$ serum insulin, diastolic blood pressure, and lower serum HDL cholesterol (data not shown).

\section{Association between apoE phenotype and glycaemic control}

Serum glycated proteins, fasting blood glucose, and $2 \mathrm{~h}$ blood glucose were higher in the apoE E2 group than in other groups (Table 1). The AGT subjects with an apoE E2 allele had highest levels of serum glycated proteins $\left[F_{2,527}=7.19, P<0.001\right.$ for the interaction] (Fig. 1), fasting blood glucose $\left[F_{2,527}=99.7, P<0.003\right.$ for the interaction] (data not shown) and $2 \mathrm{~h}$ blood glucose $\left[F_{2,527}=6.45, P<0.002\right.$ for the interaction $]$ (Fig. 2).

\section{Association between apoE phenotype, AGT and cognitive function}

Executive or memory functions did not differ in the different apoE groups or between the AGT and NGT groups (data not shown). However, the subjects with AGT and the apoE E2 allele performed worst on Trail Making Test $\mathrm{B}$ after adjustment for education and age group
(Table 2). The performance was, nevertheless, within normal range. Although the variance in Trail Making Test was greatest in subjects with the apoE E2 allele with AGT, the median of Trail Making Test was also lower in this group than in the other groups. Furthermore, the median was close to the mean in the apoE E2 group. Men with the apoE E2 allele and AGT also performed worst in Trail Making Test B-A (Table 2). The results of Trail Making Test A and word list learning did not differ between the groups. The analyses were also performed in the IGT, NIDDM, and NGT groups, but the results were essentially the same.

\section{Analyses of possible confounding factors}

When serum glycated proteins, fasting blood glucose, blood $2 \mathrm{~h}$ glucose, fasting insulin, $2 \mathrm{~h}$ insulin, serum HDL cholesterol, or BMI was used alone as a covariate, the results did not change (data not shown). When education and age group were added into model as covariates, together with serum glycated proteins, fasting blood glucose, $2 \mathrm{~h}$ blood glucose, or fasting insulin, the results did not change (Table 3 ). The regression coefficients and $95 \%$ confidence intervals of the relationship of abnormal glucose tolerance and apoE E2 phenotype compared to other apoE phenotypes and glucose tolerance groups to Trail Making Test B and Trail Making Test B-A are presented in Table 3 . When age group without education was in the model with serum glycated proteins, fasting blood glucose, $2 \mathrm{~h}$ blood glucose, or fasting insulin, the significance disappeared. Potentially mediating factors such as cardiovascular diseases, i.e. cardiomyopathia, cardiac insufficiency, angina pectoris, claudication or hypertension, and medications, i.e. any drug for hypertension, diuretics, or any $\beta$-blocker, did not explain the results. The exclusion of stroke patients from the analyses did not change the results.

\section{Discussion}

In the present study, subjects with the apoE E2 allele had poorer glycaemic control than subjects with other apoE phenotypes. Subjects with AGT and apoE E2 allele also performed less well in their cognitive executive control compared to those with other apoE phenotypes or NGT. We did not find any independent association between cognitive function and AGT or between cognitive function and apoE phenotype.

The association of apoE phenotype and abnormalities of glucose regulation has been previously studied in patients with dementia. Hyperinsulinaemia was associated with an increased risk for Alzheimer's disease in nondiabetic subjects without the ApoE E4 allele [20]. Higher fasting plasma insulin levels and reduced cerebrospinal fluid-toplasma insulin ratios, indication of insulin resistance, have 
Table 1 Characteristics of subjects with different apolipoprotein E (apoE) phenotypes

\begin{tabular}{|c|c|c|c|c|}
\hline & $\begin{array}{l}\text { ApoE E2 } \\
(N=43) \\
\text { Mean (SD) } \\
\text { or } \%\end{array}$ & $\begin{array}{l}\text { ApoE E3 } \\
(N=319) \\
\text { Mean (SD) } \\
\text { or } \%\end{array}$ & $\begin{array}{l}\text { ApoE E4 } \\
(N=166) \\
\text { Mean (SD) } \\
\text { or } \%\end{array}$ & $P^{1}$ \\
\hline 54 year-old age group & 5.1 & 30.6 & 16.1 & Ns \\
\hline 60 year-old age group & 3.0 & 29.7 & 15.3 & Ns \\
\hline Education, years & $8.8(3.0)$ & $8.2(3.0)$ & $7.6(2.9)$ & Ns \\
\hline Body mass index $\left(\mathrm{kg} / \mathrm{m}^{2}\right)$ & $28.4(4.6)$ & $27.4(3.4)$ & $27.8(3.9)$ & Ns \\
\hline Waist-to-hip ratio & $1.02(0.04)$ & $1.00(0.05)$ & $1.01(0.04)$ & Ns \\
\hline Serum glycated proteins (Umol/L) & $246.0(41.1)$ & $237.7(26.7)$ & $239.90(34.7)$ & Ns \\
\hline Fasting blood glucose $(\mathrm{mmol} / \mathrm{L})$ & $5.6(1.7)$ & $5.0(0.9)$ & $5.2(1.5)$ & 0.007 \\
\hline $2 \mathrm{~h}$ blood glucose $(\mathrm{mmol} / \mathrm{L})$ & $6.8(4.3)$ & $5.8(2.3)$ & $6.5(3.2)$ & 0.016 \\
\hline Fasting serum insulin (mUL/L) & $10.4(8.0)$ & $7.7(4.5)$ & $9.3(7.4)$ & 0.001 \\
\hline $2 \mathrm{~h}$ serum insulin $(\mathrm{mUL} / \mathrm{L})$ & $55.1(47.9)$ & $52.9(41.7)$ & $63.9(67.2)$ & 0.079 \\
\hline Serum HDL cholesterol $(\mathrm{mmol} / \mathrm{L})$ & $1.1(0.3)$ & $1.1(0.3)$ & $1.0(0.3)$ & 0.083 \\
\hline Systolic blood pressure (mmHg) & $144.0(19.5)$ & $138.8(16.8)$ & $138.6(15.4)$ & Ns \\
\hline Diastolic blood pressure (mmHg) & $93.0(9.6)$ & $88.4(10.3)$ & $88.9(9.5)$ & 0.018 \\
\hline Stroke \% & 2.3 & 3.4 & 4.8 & Ns \\
\hline Cardiomyopathia \% & 0 & 0.9 & 1.2 & Ns \\
\hline Cardiac insufficiency $\%$ & 11.6 & 9.7 & 11.4 & Ns \\
\hline Angina pectoris $\%$ & 20.9 & 19.5 & 24.1 & Ns \\
\hline Claudication \% & 9.3 & 8.2 & 5.5 & Ns \\
\hline Hypertension \% & 48.8 & 33.0 & 42.2 & Ns \\
\hline Drug for hypertension $\%$ & 46.5 & 32.3 & 44.0 & Ns \\
\hline Diuretics \% & 4.7 & 2.2 & 4.2 & Ns \\
\hline Any $\beta$-blocker \% & 11.6 & 14.1 & 19.3 & Ns \\
\hline Diabetes/IGT \% & $11.6 / 23.3$ & $6.3 / 19.7$ & $10.8 / 19.3$ & Ns \\
\hline Diabetes four years earlier \% & 9.3 & 2.5 & 4.8 & 0.064 \\
\hline
\end{tabular}

$P^{1}=$ Analysis of variance, main effect of apoE group.

been observed in patients with Alzheimer's disease who do not possess an apolipoprotein $\mathrm{E}$ e4 allele [21]. This finding suggests that there is a difference in insulin metabolism in E4 homozygotes compared with the non-E4 homozygotes with respect to Alzheimer's disease. In the present study, the highest fasting and $2 \mathrm{~h}$ blood glucose, and fasting serum insulin values were associated with apoE E2 allele in a normal population.

The mechanisms of cognitive impairment related to NIDDM are not fully understood. The chronic hyperglycaemia, typical of NIDDM, may link diabetes and cognitive function. Epidemiological studies have found poorer cognitive performance to be associated with NIDDM $[22,23]$ and with impaired glucose tolerance [24,25]. Longitudinal studies have also shown an association between diabetes mellitus and Alzheimer's disease $[26,27]$. Some have demonstrated that poor glycaemic control as assessed by $\mathrm{HbA}_{1 \mathrm{c}}$ correlates with cognitive decrement $[9,28,29]$ but others have not $[30,31]$. No correlation has been found between cognitive performance and fasting blood glucose [28,32]. In a small clinical sample, improved glycaemic control in the elderly patients with NIDDM led to better cognitive performance [33]. Impaired verbal memory has been most frequently found

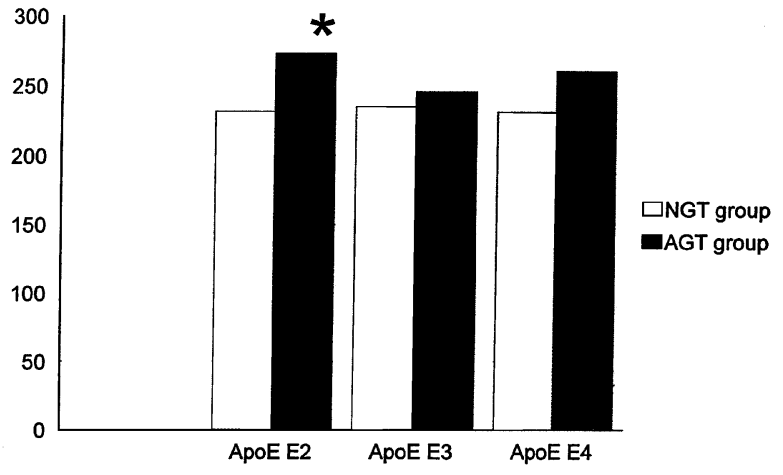

Analysis of variance, adjusted for age, " For interaction $P<0.001$

Figure 1 Serum glycated proteins (umol/L) in different apoE groups with normal (NGT) and abnormal (AGT) glucose tolerance.

[28-30,34] but associations with impaired attention or concentration $[29,35,36]$ have also been reported. The formation of advanced glycation end products contribute to the pathogenesis of diabetic complications, but could contribute to the characteristic protein deposits in Alzheimer's disease, including neurofibrillary tangles and beta-amyloid plaques $[37,38]$. However, the serum 
glycated proteins did not differ between apoE groups in the present study.

Duration of diabetes has been related to cognitive decline [22,40]. Croxson et al. [41] reported that those with known diabetes were more likely than normal subjects to have a low Mini Mental Status Examination score, while newly diagnosed diabetic subjects did not. However, we do not know how long the glycaemic control has been poor in our subjects.

Insulin might also affect neuronal activity and cognition. An association between high postload insulin and glucose levels, and poor cognitive function has been reported [23]. Moreover, Craft et al. [42] recently showed that insulin administration improved memory performance in Alzheimer's disease subjects without an $\varepsilon 4$ allele, whereas the memory performance of the Alzheimer's disease $\varepsilon 4$ patients did not improve. This suggests that glycaemic control may be related to cognitive impairment in a subgroup of Alzheimer's disease patients only. This is

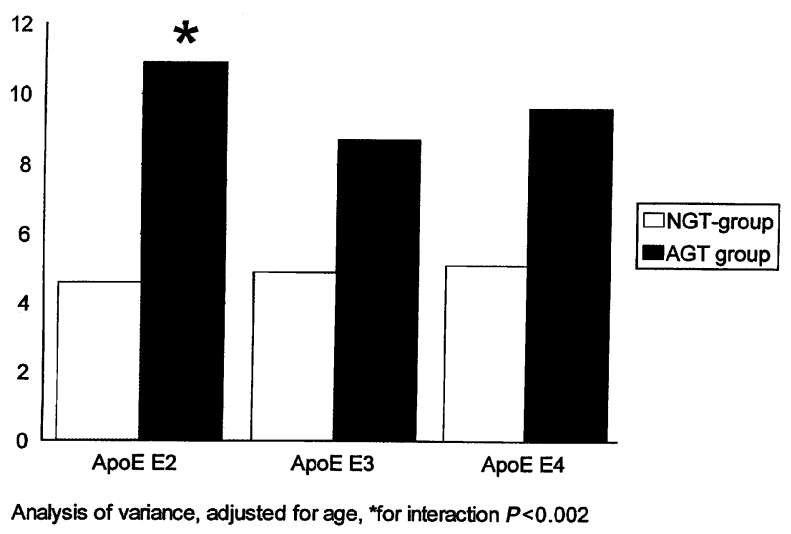

Figure $22 \mathrm{~h}$ blood glucose $(\mathrm{mmol} / \mathrm{L})$ in glucose tolerance test in different apoE groups with normal (NGT) and abnormal (AGT) glucose tolerance. partly supported by our observation that only subjects with an apoE E2 allele and AGT performed more poorly than those with AGT and other alleles.

Table 3 Regression coefficients (95\% Confidence interval) of abnormal glucose tolerance and apoE E2 phenotype to Trail Making Test B and Trail Making Test B-A

\begin{tabular}{lll}
\hline & $\begin{array}{l}\text { Trail Making Test B } \\
\beta \text {-coefficient }(95 \% \mathrm{CI})\end{array}$ & $\begin{array}{l}\text { Trail Making Test B-A } \\
\beta \text {-coefficient }(95 \% \text { CI })\end{array}$ \\
\hline Model 1: & $58.61(11.85-105.37)$ & $52.68(13.47-91.88)$ \\
Model 2: & $65.07(21.52-108.62$ & $57.36(20.14-94.59)$ \\
Model 3: & $56.21(12.84-99.57)$ & $50.01(12.92-87.10)$ \\
Model 4. & $55.16(11.75-98.56)$ & $48.89(11.78-85.99)$ \\
Model 5: & $55.13(11.68-98.58)$ & $48.72(11.58-85.85)$ \\
Model 6: & $56.39(12.86-99.92)$ & $49.44(12.22-86.65)$ \\
Model 7: & $56.47(13.12-99.94)$ & $50.32(13.14-87.49)$ \\
Model 9: & $56.15(12.75-99.55)$ & $49.98(12.86-87.11)$ \\
Model 10: & $57.25(14.17-100.87)$ & $50.99(13.89-88.09)$ \\
Model 11: & $56.19(12.75-99.63)$ & $49.90(12.74-87.05)$ \\
\hline
\end{tabular}

Model 1: Unadjusted association of AGT $\times$ apoE E2

Model 2: Controlling for education

Model 3: Controlling for education and age group

Model 4: Controlling for education, age group, and serum glycated proteins

Model 5: Controlling for education, age group, and fasting blood glucose

Model 6: Controlling for education, age group, and $2 \mathrm{~h}$ blood glucose $(\mathrm{mmol} / \mathrm{L})$

Model 7: Controlling for education, age group, and fasting serum insulin $(\mathrm{mUL} / \mathrm{L})$

Model 8: Controlling for education, age group, and serum triglycerides $(\mathrm{mmol} / \mathrm{L})$

Model 9: Controlling for education, age group, and diastolic blood pressure $(\mathrm{mmHg})$

Model 10: Controlling for education, age group, and body mass index $\left(\mathrm{kg} / \mathrm{m}^{2}\right)$

Model 11: Controlling for education, age group, serum glycated proteins, fasting blood glucose, $2 \mathrm{~h}$ blood glucose ( $\mathrm{mmol} / \mathrm{L})$, fasting serum insulin $(\mathrm{mUL} / \mathrm{L})$, triglycerides $(\mathrm{mmol} / \mathrm{L})$, diastolic blood pressure $(\mathrm{mmHg})$, and body mass index $\left(\mathrm{kg} / \mathrm{m}^{2}\right)$.

Table 2 Executive and memory function in men with abnormal glucose tolerance (AGT) and normal glucose tolerance (NGT) with different apolipoprotein E phenotypes (apoE)

\begin{tabular}{|c|c|c|c|c|c|c|c|c|c|}
\hline & \multicolumn{3}{|c|}{ Abnormal glucose tolerance (AGT) } & \multicolumn{3}{|c|}{ Normal glucose tolerance (NGT) } & \multirow[b]{2}{*}{$P^{1}$} & \multirow[b]{2}{*}{$P^{2}$} & \multirow[b]{2}{*}{$P^{3}$} \\
\hline & $\begin{array}{l}\text { ApoE E2 } \\
(N=15) \\
\text { Mean (SD) }\end{array}$ & $\begin{array}{l}\text { ApoE E3 } \\
(N=83) \\
\text { Mean (SD) }\end{array}$ & $\begin{array}{l}\text { ApoE E4 } \\
(N=50) \\
\text { Mean (SD) }\end{array}$ & $\begin{array}{l}\text { ApoE E2 } \\
(N=28) \\
\text { Mean }(\mathrm{SD})\end{array}$ & $\begin{array}{l}\text { ApoE E3 } \\
(N=235) \\
\text { Mean }(S D)\end{array}$ & $\begin{array}{l}\text { ApoE E4 } \\
(N=116) \\
\text { Mean }(S D)\end{array}$ & & & \\
\hline Trail Making A & $51.7(15.0)$ & $53.9(17.2)$ & $48.7(15.5)$ & $52.3(16.9)$ & $52.3(20.0)$ & $55.3(20.7)$ & Ns & 0.000 & 0.061 \\
\hline Trail Making B & $145.1(89.5)$ & $131.0(64.5)$ & $123.7(70.3)$ & $102.0(48.0)$ & $121.5(63.2)$ & $139.3(68.1)$ & 0.027 & 0.001 & 0.001 \\
\hline Trail Making B-A & $93.2(81.2)$ & $77.5(56.4)$ & $75.0(59.6)$ & $49.6(44.0)$ & $69.2(50.0)$ & $84.1(58.9)$ & 0.029 & 0.001 & 0.001 \\
\hline List learning & $34.1(7.9)$ & $33.1(8.1)$ & $34.6(7.9)$ & $34.7(8.1)$ & $34.7(8.7)$ & $33.7(8.9)$ & Ns & 0.001 & 0.015 \\
\hline
\end{tabular}

Analysis of variance, adjusted for agegroup and education, $P^{1}$ Interaction between AGT and ApoE groups, $P^{2}$ Effect of education, $P^{3}$ Effect of age group. The values of cognitive tests are within normal range. 
It is possible that other aspects related to the insulin resistance syndrome, such as accelerated atherosclerosis [14], could explain the association between the insulin resistance syndrome and cognitive impairment in elderly. It has been suggested that the presence of apolipoprotein $\mathrm{E}$ phenotypes containing the $\varepsilon 4$ allele, cerebrovascular disease [14] and cardiovascular risk factors or subclinical cardiovascular disease [43] may act synergistically on cognitive decline.

The absolute postprandial triglyceridaemia was highest in subjects with apolipoprotein E2 allele [44]. They also had increased factor (VIIa) activity during postprandial triglyceridaemia. In the present study, the apoE E2 allele group had higher serum triglycerides and diastolic blood pressure. However, there was no difference in the prevalence of cardiovascular diseases between the groups.

These exploratory analyses revealed that subjects with an apoE E2 allele and AGT exhibited worse cognitive executive control than other subjects. They also had worse glycaemic control. Different apolipoprotein phenotypes, together with impaired glucose tolerance, may have different cumulative adverse effects on age-related cognitive performance. Some subgroups of subjects may be especially vulnerable to cognitive impairment. These findings require further study.

\section{Acknowledgements}

We thank Kimmo Ronkainen for data analyses, Kari Seppänen and Kristina Nygssönen for biochemical analyses, and our staff for data collection, and the Academy of Finland; the Finnish Ministry of Education; and the National Heart, Lung and Blood Institute of the United States (grant HL44199). T.L. was a postdoctoral researcher of the Academy of Finland.

\section{References}

1 Corder EH, Saunders AM, Strittmacher WJ, Schmechel DE, Gaskell PC, Small GW et al. Gene dose of apolipoprotein E type 4 allele and the risk of Alzheimer's disease in late onset families. Science 1993; 261: 921-923.

2 Kuusisto J, Koivisto K, Kervinen K, Mykkänen L, Helkala E-L, Vanhanen $\mathrm{M}$ et al. Association of apolipoprotein E phenotypes with late onset alzheimer's disease: population based study. $\mathrm{Br}$ Med J 1994; 309: 636-638.

3 Reed T, Carmelli D, Swan GE, Breitner JCS, Welsh KA, Jarvik GP $e t$ al. Lower cognitive performance in normal older adult male twins carrying the apolipoprotein E $\varepsilon 4$ allele. Arch Neurol 1994; 51: 1189_ 1192.

4 Bondi MW, Salmon DP, Monsch AU, Galalsko D, Butters N, Klauber MR et al. Episodic memory changes are associated with the ApoE- 84 allele in nondemented older adults. Neurology 1995; 45: 2203-2206.

5 Yaffe K, Cauley J, Sands L, Browner W, Apolipoprotein E phenotype and cognitive decline in a prospective study of elderly community women. Arch Neurol 1997; 54: 1110-1114.

6 Louhija J, Miettinen HE, Kontula K, Tikkanen MJ, Miettinen TA,
Tilvis RS. Aging and genetic variation of plasma apolipoproteins. Relative loss of the apolipoprotein e4 phenotype in centenarians. Arterioscler Tromb 1994; 14: 1084-1089.

7 Helkala E-L, Koivisto K, Hänninen T, Vanhanen M, Kervinen K, Kuusisto $\mathrm{J}$ et al. The association of apolipoprotein E polymorphism with cognitive performance: population based study. Neurosci Lett 1995; 191: 141-144.

8 Helkala E-L, Koivisto K, Hänninen T, Vanhanen M, Kervinen K, Kuusisto J et al. Memory functions in human subjects with different apolioprotein E phenotypes during a 3-year population-based follow-up study. Neurosci Lett 1996; 204: 177-180.

9 U'Ren R, Riddle MC, Lezak MD, Bennington-Davis M. The mental efficiency of the elderly person with type II diabetes mellitus. $J \mathrm{Am}$ Geriatric Soc 1990; 38: 505-510.

10 Tun PA, Nathan DM, Perlmuter LC. Cognitive and affective disorders in elderly diabetics. Clin Geriatr Med 1990; 6: 731-746.

11 Helkala E-L, Niskanen L, Viinamäki H, Partanen J, Uusitupa M. Short-term and long-term memory in elderly patients with NIDDM. Diabetes Care 1995; 18: 681-685.

12 Strachan MWJ, Deary IJ, Ewing FME, Frier BM. Is type II diabetes associated with an increased risk of cognitive dysfunction? Diabetes Care 1997; 20: 438-445.

13 Kalmijn S, Feskens EJ, Launer LJ, Kromhout D. Cerebrovascular disease, the apolipoprotein e4 allele, and cognitive decline in a community-based study of elderly men. Stroke 1996; 27: 22302235.

14 Hofman A, Ott A, Breteles MMB, Bots ML, Slooter AJC, vanHarskamp $\mathrm{F}$ et al. Atherosclerosis, apolipoprotein-E and the prevalence of dementia and Alzheimer's disease in the Rotterdam study. Lancet 1997; 349: 151-154.

15 Salonen JT. Is there a continuing need for longitudinal epidemiological research? The Kuopio Ischaemic heart disease risk factor study. Ann Clin Res 1988; 20: 46-50.

16 World Health Organization. Diabetes Mellitus. Report of a WHO Study Group. Technical Report Ser No. 727, World Health Org, Geneva 1985.

17 Ehnholm C, Lukka M, Kuusi T, Nikkilä E, Uterman G, Apolipoprotein E polymorphism in the Finnish population: gene frequencies and relation to lipoprotein concentration. J Lipid Res 1986; 27: 227-235.

18 Buschke H, Fuld PS. Evaluating storage, retention, and retrieval in disordered memory and learning. Neurology 1974; 24: 1019-1025.

19 Reitan RM. Validity of the Trail Making test as an indicator of organic brain damage. Percept Motor Skills 1958; 8: 271-276.

20 Kuusisto J, Koivisto K, Mykkänen L, Helkala E-L, Vanhanen M, Hänninen T. Association between features of the insulin resistance syndrome and Alzheimer's disease independently of apolipoprotein e4 phenotype: cross sectional population based study. BMJ 1997; 315: 1045-1048.

21 Craft S, Peskind E, Schwartz MW, Schellenberg GD, Raskind M, Porte D. Cerebrospinal fluid and plasma insulin levels in Alzheimer's disease: relationship to severity of dementia and apolipoprotein E phenotype. Neurology 1998; 50: 164-168.

22 Elias PK, Elias MF, D’Agostino RB, Cupples LA, Wilson PW, Silberhatz $\mathrm{H}$ et al. NIDDM and blood pressure as risk factors for poor cognitive performance. The Framingham Study. Diabetes Care 1997; 20: 1388-1395.

23 Scott RD, Kritz-Silverstein D, Barret-Connor E, Wiederholt WC. The association of non-insulin-dependent diabetes mellitus and cognitive function in an older cohort. J Am Geriatr Soc 1998; 46: 1217-1222.

24 Vanhanen M, Koivisto K, Kuusisto J, Mykkänen L, Helkala E-L, Hänninen $\mathrm{T}$ et al. Cognitive function in an elderly population with persistent impaired glucose tolerance. Diabetes Care 1998; 21: 398_ 402. 
25 Kalmijm S, Feskens EJM, Launer LJ, Kromhout D. Glucose intolerance, hyperinsulinemia and cognitive function in a general population of elderly men. Diabetologia 1995; 38: 1096-1102.

26 Leibson CL, Rocca WA, Hanson VA, Cha R, Kokmen E, O’Brian PC et al. Risk of dementia among persons with diabetes mellitus: a population-based cohort study. Am J Epidemiol 1997; 145: 301308.

27 Ott A, Stolk RP, van Harskamp F, Pols HAP, Hofman A, Breteler MMB. Diabetes mellitus and risk of dementia in a elderly population. The Rotterdam Study. Neurol 1999; 53: 1907-09.

28 Perlmuter LC, Hakami MK, Hodgson-Harrington C, Ginsberg J, Katz J, Singer DE et al. Decreased cognitive function in aging noninsulin-dependent diabetic patients. Am J Med 1984; 77: 10431048.

29 Jagusch W, Cramon DYV, Renner R, Hepp KD. Cognitive function and metabolic state in elderly diabetic patients. Diabetes Nutr Metab 1992; 5: 265-274.

30 Worrall G, Moulton N, Briffett E. Effect of type II diabetes mellitus on cognitive function. J Fam Pract 1993; 36: 639-643.

31 Lowe LP, Tranel DT, Wallace RB, Welty TK, Type II diabetes and cognitive function. Diabetes Care 1994; 17: 891-896.

32 Ryu N, Chin K. Decreased brain function in patients with noninsulin-dependent diabetes mellitus (in Japanese). No Shinkei 1995; 47: 543-548.

33 Meneilly GS, Hill A. Alterations in glucose metabolism in patients with Alzheimer's disease. J Am Geriatr Soc 1993; 41: 710-714.

34 Reaven GM, Thompson LW, Nahum D, Haskins E. Relationship between hyperglycemia and cognitive function in older NIDDM patients. Diabetes Care 1990; 13: 16-21.

35 Mooradian AD, Perryman K, Fitten J, Kavonian GD, Morley JRE. Cortical function in elderly non-insulin dependent diabetic patients. Behavioral and electrophysiologic studies. Arch Intern Med 1988; 148: 2369-2372.
36 Meuter F, Thomas W, Grüneklee D, Gries FA, Lohmann R. Psychometric evaluation of performance in diabetes mellitus. Horm Metab Res 1980; 9: 9-17.

37 Sasaki N, Fukatsu R, Tsuzuki K, Hayashi Y, Yoshida T, Fujii N. Advanced glycation end products in Alzheimer's disease and other neurodegenerative diseases. Am J Pathol 1998; 153: 1149-1150.

38 Messier C, Gagnon M. Glucose regulation and cognitive functions: relation to Alzheimer's disease and diabetes. Behav Brain Res 1996; 75: 1-11.

39 Gregg EW, Yaffe K, Cauley JA, Rolka DB, Blackwell TL, Nrayan $\mathrm{KM}$ et al. Is diabetes associated with cognitive impairment and cognitive decline among older women? Study Osteoporotic Fractures Res Group. Arch Intern Med 2000; 160: 174-180.

40 Croxson SC, Jagger C. Diabetes and cognitive impairment: a community-based study of elderly subjects. Age Ageing 1995; 24 : 421-424.

41 Stolk RP, Breteler MMB, Ott A, Pols HAP, Lamberts SWJ, Grobbee DE et al. Insulin and cognitive function in an elderly population. Diabetes Care 1997; 20: 792-794.

42 Craft S, Asthana S, Schellenberg G, Baker L, Cherrier M, Boyt AA et al. Insulin effects on glucose metabolism, memory, and plasma amyloid precursor protein in Alzheimer's disease differ according to apolipoprotein-E phenotype. Ann N Y Acad Sci 2000; 903: 222-228.

43 DeCarli C, Reed T, Miller BL, Wolf PA, Swan GE, Carmelli D. Impact of apolipoprotein E epsilon4 and vascular disease on brain morphology in men from the. NHLBI twin study. Stroke 1999; 30: 1548-1553.

44 Nordoy A, Bonaa KH, Sandset PM, Hansen JB, Nilsen H. Relationship between apolipoprotein E polymorphism, postprandial hyperlipemia and hemostatic variables in patients with combined hyperlipemia. Nutr Metab Cardiovasc Dis 2000; 10: 15-23. 